\title{
Measurement Control of Ready-Made Garments with Image Analysis Methods
}

\author{
Özge Ural, Tuba Vural \\ Gazi University, Department of Clothing Industry and Fashion Design, Ankara, Türkiye
}

Corresponding Author: Özge Ural, ozgeural@gazi.edu.tr

\begin{abstract}
In the ready-made clothing industry accurate garment measurement is one of the most important points for the right fitting of the apparel. Garments should be produced to the determined size by the customer or the enterprise. Although, the measurement control of the final product is made by trained operator, the factors such as gradually loose of attention, fatigue and stress could cause faults that could lead to lack of quality and waste of time. In this sense, developing and using objective, fast and economic measurement control systems in terms of both cost effectiveness and the reliability of the controls has become a must. The purpose of the study is to design a system and develop an algorithm to control the measurements of garments automatically. This study, which is determined that image analysis method can be used in measurement control of ready-made garments, will be a new measurement control method in the literature and an example for similar studies. By benefiting from the image analysis methods, measurement mistakes likely to result from the operator will be prevented and the results will be made more reliable.
\end{abstract}

\author{
ARTICLE HISTORY \\ Received: 05.04.2019 \\ Accepted: 16.12.2019
}

\section{KEYWORDS}

ready-made garments, quality control, image analysis methods, measurement control

\section{INTRODUCTION}

In apparel industry, measurement control is extremely critical in terms of being an important criterion affecting cloth fitting. Ready-made garments, where physical appearance and body fit are extremely important, should be produced to the determined size by the customer or the enterprise.

For apparel products, fit of the garments is one of the most important parameters affecting the customer satisfaction and the buying decision [1]. Manufacturers should keep control of their finished garments measurements and remove or repair the products exceeding the specified tolerances. Because measurement problems are an important issue affecting the quality of the product.

However, finished and semi-finished products may be subjected to conditions that may cause measurement deviations at all stages of production. Measurement problems in the product may be caused by incorrect methods or applications in various departments, or material properties. Storage conditions and methods that do not conform to the structural properties of the fabric or auxiliary materials may cause tension or shrinkage on the fabric. In the cutting section; at the process of fabric control, fabric laying, cutting, sorting and sewing preparation, working with methods that are not suitable for fabric properties negatively affect the dimensions of the products. In the sewing section; wrong machine settings, false sewing techniques, and operator application errors result in deviations in measurement. In the ironing section; incorrect ironing setting, operator's lack of information, lack of skill or carelessness can cause differences in measure. And finally, in the quality control and packaging department; storage method of finished products and storage errors (storage environment, moisture content, etc.) can cause problems in the measurements. To keep measurements under control, semi-finished and finished garments are measured in line and final control stage of the production.

To cite this article: Ural Ö, Vural T. 2020. Measurement control of ready-made garments with 1mage analysis methods. Tekstil ve Konfeksiyon 30(1), pp:73-79. 
The efficiency of the measurement control which is under the responsibility of quality control operator is affected by the knowledge and skills of the employee as well as by physical (tiredness, attention etc.) and mental structures (stress, unwillingness, depression, etc.). The cognitive and affective behaviour of the operator can cause errors, losses of time and quality during the control and decision stages.

Acceleration of the entry into storage of finished products towards the end of the production process, the approach of the shipment date, customers pressures, the differences between planned and actual targets create stress and pressure on the quality control department which is the most critical department.

In the final control department, the product's measurement controls are performed according to the locations and positions specified in the measurement table, unless specific criteria or methods are specified by the customers. It is necessary that measurement deviations must not be out of determined tolerances. However, all measurements of all products cannot be controlled in terms of lack of time and labor costs. Therefore, critical measurements (chest width, length, etc.) are often checked by simple random sampling.

Considering the importance of measurement control; it should not be ignored that the intense tempo and stress in the enterprises affect the efficiency, accuracy and effectiveness of the measurement control. Measurement controls should be performed carefully and accurately to ensure that the product can be produced in desired specifications and to ensure customer satisfaction. In this sense, developing and using objective, fast and economic measurement control systems in terms of both cost effectiveness and the reliability of the controls has become a must.

The purpose of the study is to design a system and develop an algorithm to control the measurements of garments automatically. The system will be simple, portable and easily adaptable to computers. The measurement control system will enhance product quality and result in improved productivity to meet both customer demands and reduce costs associated with off-quality. The employment cost will be reduced by automatic control of measurement, where deviations in measurements will be evaluated objectively. A database of the measurements can be formed and they can then be analysed realistically. Consequently, statistical evaluation of measurements can be achieved.

Today, visual analysis systems are used as a fast and effective method in the controls of various products in textile and ready-made clothing industry. The use of image analysis to replace human vision is now wide spread in industrial manufacture; there are many benefits in reducing fatigue and improving speed, consistency and cost effectiveness. The image analysis system is referred to realising visual function of human, i.e. realizing the recognition of three- dimensional objective world, by means of computer [2].

Nowadays, picture processing has many applications in different fields such as textile industry, garment industry and measurement. Among the uses are: automatic measurement of coverage factor, control of thread defects, measurement of length and diameter of thread and fibers, measurement of shining index, investigation of the thickness of the cloth and its other features, measurement of torsion angle of cloth and measurement and modelling the body [3].

Image processing techniques in textile sector are used for the purpose of structural investigation, classification, defect detection and quality control in fibre, yarn and fabric surfaces. In line with technological developments, the number and variety of the studies carried out in the literature is getting increased. Upon the review of the related literature, it is likely to see that image analysis methods were studies into various fibres, yarns, woven and knitted fabrics, nonwoven fabrics at a large scale but were not studied into the ready-made garments at an adequate number.

Chen [2] used the fuzzy edge-detection algorithm to detect the edges of garment, and found the key corner points based on Freeman chain codes. Cao et al [4] adopted median filter algorithm to eliminate the garment image noise and is used a fast fuzzy edge-detection algorithm to detect the edge of garment image; and invoked a new corner-detection algorithm based on Freeman code to locate the corner points. Li et al [5] proposed an automatic garment measurement approach using image recognition. A garment template is introduced to recognize garment types and feature points, which are used to calculate the garment sizes. Roknabadi et al [3] made a new device to take human body's measures in cloth using image processing. Their method based on image processing which can extract the main measurements of the body based on Muller method. In the related literature, the studies carried out into garments highlight the efficiency of this method.

In this study Faster Region-based Convolutional Neural Network was used instead of other object detection algorithms as it has better process time and accuracy and it is more current and accepted algorithm.

The purpose of the current study was to find an answer to the question of whether the use of image analysis method was effective in the measurement control of the finished ready-made garments for the first time, in the light of the studies conducted in the literature [6].

\section{MATERIAL AND METHODS}

As the current study is one of the first research and development one carried out into the use of image analysis method on ready-made garments, the sampling group was determined as a round-necked and short-sleeved white T- 
shirt by paying attention to the fact that it is a simple model to be studied and to the need that the product should have suitable model and colour in taking a photography and processing the image. The research was carried out in two stages as the pilot study and basic application.

In both studies, the applications were made through image processing programs that were developed for the research. As the data processing and building neural network, Tensorflow framework was used for the edge detection and the camera having an imaging capacity of at least 8.0 megapixel in order to obtain programs and images that was developed for the quality control of the T-shirts.

In order to run the system that was developed; it is necessary to have

1. A camera or digital CMOS (digital camera) having an imaging capacity of at least 8.0 megapixel to obtain the images

2. Tensorflow for edge detection. Faster Region-based Convolutional Neural Network was used instead of other object detection algorithms because that recently, Faster RCNN has better process time and accuracy. Faster RCNN was supported with Inception network.

3. Python program for distance calculation.

4. OpenCV Library for getting image as data.

The first trials were made in a lab in the research. A fixed platform was formed in order to conduct the control of the product and image reception processes. The camera that was planned to receive the images over the product was fixed on the platform adjacent to the light source. For lighting, softone light bulbs and fluorescent lamps were used. The picture of testing apparatus is given in Figure 1 and the main units of the system applied in the research are given in Figure 2.

The program processes over pixels. First, the distance between the pixels is calculated as shown in Equation (1). According to Equation (2), product of actual width and ratio of pixel distance to resolution gives actual distance.

$(\mathrm{x} 1, \mathrm{y} 1)=$ Coordinates of edge 1

$(\mathrm{x} 2, \mathrm{y} 2)=$ Coordinates of edge 2

Actual Width $=$ Real life distance

Resolution's width = Image Dimension

Pixel distance $=\sqrt{(x 1-x 2)^{2}+\left(y 1-y^{2}\right)^{2}}$

Actual Distance $=($ Pixel Distance $/$

Resolution's width) x Actual width

The camera takes the picture at $65 \mathrm{~cm}$ height and with the right angle. After the picture of the T-shirt was given as an input to neural network, neural network detects related edge and their coordinates. The program determines the measurement by calculating distance using by equations respectively Equation 1 and Equation 2.

The example of the flow graphics of measurement scanning is given in Figure 3.

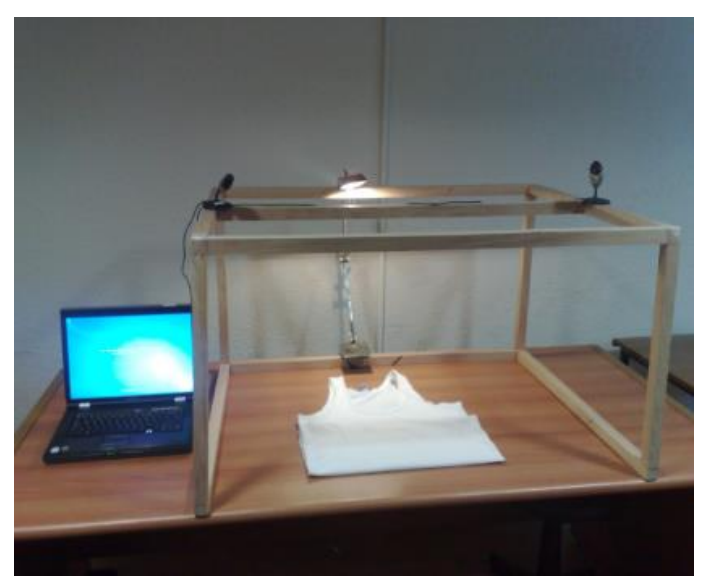

Figure 1. Testing apparatus

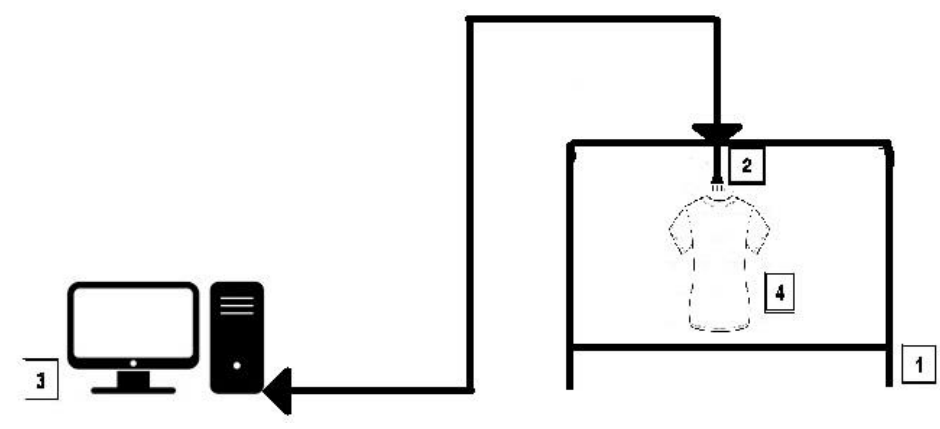

Figure 2. Main units of the system applied in the research (1) The structure allowing the electro mechanic system standstill, (2) Camera and light source, (3) Pretrained model included machine, (4) T-shirt. 


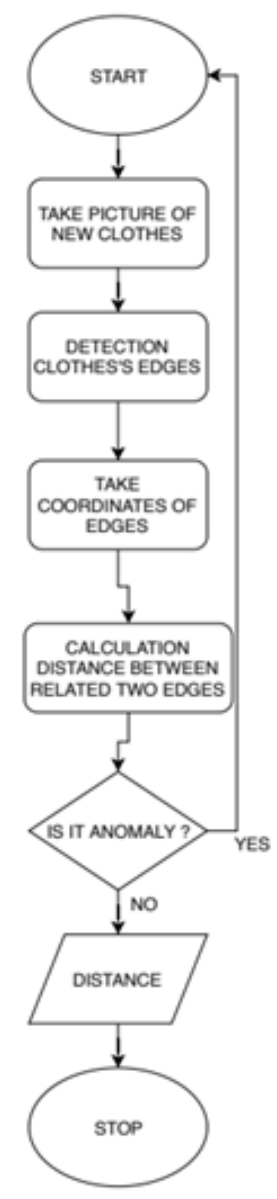

Figure 3. Flow Graphic of Measurement Scanning

In the study, $43 \mathrm{~T}$-shirts were measured by the operator and the program. $\mathrm{T}$-shirt measurement positions referenced in this research are shown in Figure 4.

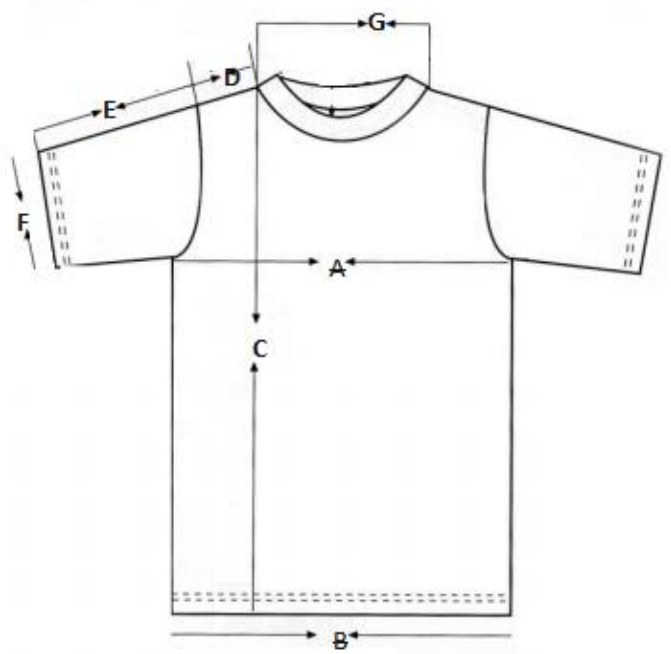

Figure 4. Measurement positions of T-shirts A: Chest B: Hem (hemline) C: Front Length D: Shoulder Width E: Sleeve Length F: Sleeve Opening G: Neck Opening.

The T-shirt measurement of the operator is shown in Figures 5 and 6.

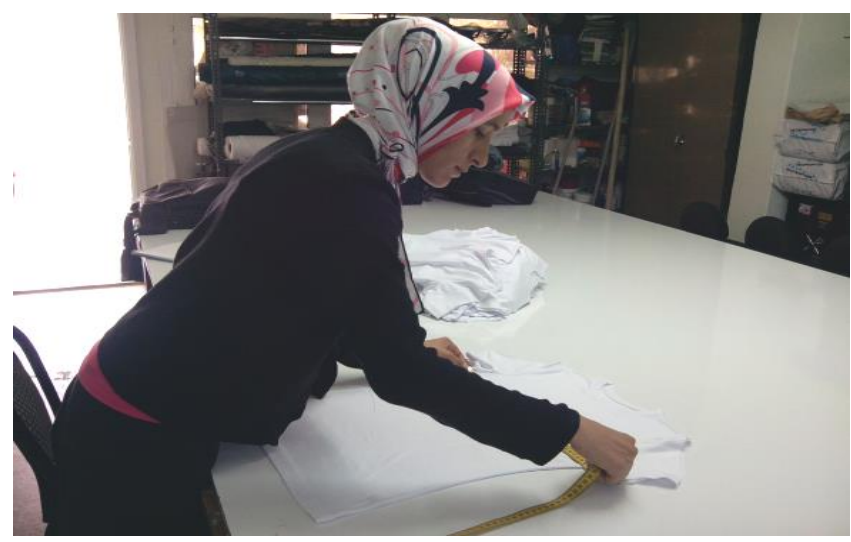

Figure 5. Operator's chest measurement

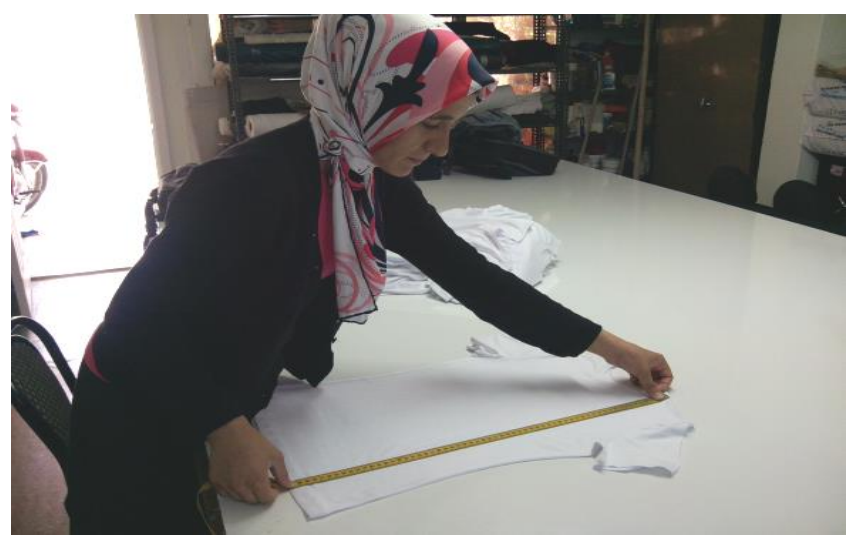

Figure 6. Operator's front length measurement

Picture of clothes is taken from pre-built, fixed platform. Taken image is given to neural network to edge detection. After neural network detects edges with tags and coordinates, software written in python calculate distance between two related edges. If output is outlier, it would be better to separate it for manual measurement. Because that, even if we have a very high success rate, we cannot rule out low errors. So, we preserve our system 10 times faster and more reliably. If the output is not anomaly, the distance will save and the process continues with new clothes.

\section{RESULTS AND DISCUSSION}

In the study carried out over the products chosen randomly in a determined work flow and time interval, the measurement results obtained with the program developed for the research were compared with the measurement results measured by the operators.

In statistics, mean absolute error (MAE) is a measure of difference between two continuous variables. In this study, they are; if we take human measurements as bayesian error, worker measurements as true values and software results. As shown in the table above, there are very small differences between the software results and the actual human measurements we accept. If the error rate is assumed to be directly proportional to the accuracy, the accuracy is expected to be high. As shown in the table above, accuracy has met the expected value. 
Table 1. MAE\&Accuracy

\begin{tabular}{|c|c|c|}
\hline & Mean Absolute Error & Accuracy \\
\hline Chest Width & 0.267442 & 99.9394 \\
\hline Hem Width & 0.0418605 & 99.9997 \\
\hline $\begin{array}{l}\text { Front Length } \\
\text { from Shoulder }\end{array}$ & 0.0465116 & 99.9997 \\
\hline Neck Opening & 0.027907 & 99.9989 \\
\hline $\begin{array}{l}\text { Right Shoulder } \\
\text { Width }\end{array}$ & 0.0302326 & 99.9985 \\
\hline $\begin{array}{l}\text { Left Shoulder } \\
\text { Width }\end{array}$ & 0.0372093 & 99.9976 \\
\hline $\begin{array}{l}\text { Right Arm } \\
\text { Width }\end{array}$ & 0.0162791 & 99.9997 \\
\hline Left Arm Width & ๑. 0953488 & 99.9912 \\
\hline $\begin{array}{l}\text { Right Sleeve } \\
\text { Opening }\end{array}$ & $\theta$ & 100 \\
\hline $\begin{array}{l}\text { Left Sleeve } \\
\text { Opening }\end{array}$ & $\Theta$ & 100 \\
\hline
\end{tabular}

As measurement results of the operator and the program have almost same values (99\% accuracy) on 43 samples, lines are overlapping in any graphics. So, no graphics is needed because of high accuracy.

The data obtained in the current study was analysed with the package program of SPSS 15.0. The frequency and percentage distributions of the data were given. The normality test of the measurement values made by operator and the program regarding the $\mathrm{T}$-shirt were analysed and it was found that not all measurement values came from normal distribution $(\mathrm{p}<0.05)$.

The evaluation of the normality test of the measurement results is given in Table 2.

During the analysis of the difference between the nonnormally distributed variables at the end of the normality test of the data, Mann Whitney U Test, which is not parametric in pair groups, was used.
Whether there was a difference between the measurements by both the operator and the program over the T-shirts was evaluated with Mann Whitney U Test. The data obtained for each measurement part were evaluated separately. The comparison of the operator and the program results for shoulder width is given in Table 3 .

Upon the comparison of the operator and the program results for the measurements of the chest width of the product, it was found that there was no significant difference between the measurements at the significant level of $\mathrm{p}>0.05$ as measurement means were the same $(\bar{x}=38,9 \mathrm{~cm})$ and $\mathrm{p}=0.542$.

At the end of the applications, the measurement results of products' chest, hem (hemline), front length from shoulder, neck opening, right-left shoulder width and right-left sleeve opening obtained with the operator and the program were compared and no significant difference was found between the measurements $(\mathrm{p}>0.05)$.

While making a comparison between the dependent variables, WilcoxonSign Test was used in non-normally distributed variables. As for the differences between the groups, significance level was regarded 0.05 and in the case of $p<0.05$, there became a significant difference between the groups and when it was $\mathrm{p}>0.05$, there did not become a significant difference between the groups.

In order to determine whether there was a compliance between the difference of the measurements taken by the operator and the program of the measurement parts which had a similarity in terms of the method and place of making measurement on the product, WilcoxonSigh test was used. The comparison of the differences of the chest width and hem width is given in Table 4.

Table 2. The normality test of the measurement results

\begin{tabular}{|c|c|c|c|c|}
\hline & \multicolumn{4}{|c|}{ Normality Test } \\
\hline & \multicolumn{4}{|c|}{ Kolmogorov-Smirnov Test } \\
\hline & & Test Statistics & Degree of Freedom & $\mathrm{P}$ \\
\hline \multirow{2}{*}{ Chest Width } & Operator & 0,214 & 43 & $0,000^{*}$ \\
\hline & Program & 0,200 & 43 & $0,000^{*}$ \\
\hline \multirow{2}{*}{ Hem (hemline) Width } & Operator & 0,259 & 43 & $0,000^{*}$ \\
\hline & Program & 0,210 & 43 & $0,000 *$ \\
\hline \multirow{2}{*}{ Front Length from Shoulder } & Operator & 0,237 & 43 & $0,000 *$ \\
\hline & Program & 0,177 & 43 & $0,002 *$ \\
\hline \multirow{2}{*}{ Neck Opening } & Operator & 0,235 & 43 & $0,000^{*}$ \\
\hline & Program & 0,174 & 43 & $0,002 *$ \\
\hline \multirow{2}{*}{ Right Shoulder Width } & Operator & 0,247 & 43 & $0,000 *$ \\
\hline & Program & 0,188 & 43 & $0,001^{*}$ \\
\hline \multirow{2}{*}{ Left Shoulder Width } & Operator & 0,329 & 43 & $0,000^{*}$ \\
\hline & Program & 0,241 & 43 & $0,000 *$ \\
\hline \multirow{2}{*}{ Right Arm Width } & Operator & 0,315 & 43 & $0,000 *$ \\
\hline & Program & 0,289 & 43 & $0,000 *$ \\
\hline \multirow{2}{*}{ Left Arm Width } & Operator & 0,392 & 43 & $0,000^{*}$ \\
\hline & Program & 0,263 & 43 & $0,000 *$ \\
\hline \multirow{2}{*}{ Right Sleeve Opening } & Operator & 0,463 & 43 & $0,000^{*}$ \\
\hline & Program & 0,463 & 43 & $0,000 *$ \\
\hline \multirow{2}{*}{ Left Sleeve Opening } & Operator & 0,419 & 43 & $0,000 *$ \\
\hline & Program & 0,419 & 43 & $0,000^{*}$ \\
\hline
\end{tabular}

$* \mathrm{p}<0,05$ 
Table 3. Comparison of operator and program results for the shoulder width measurement

\begin{tabular}{|c|c|c|c|c|c|c|c|c|c|c|}
\hline \multirow[b]{2}{*}{ Measurement Part } & & \multicolumn{9}{|c|}{ Mann Whitney U Test } \\
\hline & & $\mathrm{n}$ & Mean & Median & Minimum & Maximum & SS & Mean Rank & $\mathrm{U}$ & $\mathrm{p}$ \\
\hline \multirow{3}{*}{ Shoulder Width } & Operator & 43 & 38,9 & 39,0 & 37,5 & 40,0 & 0,5 & 41,9 & \multirow{3}{*}{856} & \multirow{3}{*}{0,542} \\
\hline & Program & 43 & 38,9 & 39,0 & 37,4 & 40,0 & 0,5 & 45,1 & & \\
\hline & Total & 86 & 38,9 & 39,0 & 37,4 & 40,0 & 0,5 & & & \\
\hline
\end{tabular}

$\mathrm{p}>0,05$

Table 4. Comparison of chest and hem (hemline) differences

\begin{tabular}{|c|c|c|c|c|c|c|c|c|c|c|c|c|c|}
\hline \multicolumn{14}{|c|}{ Wilcoxon Sign Test } \\
\hline & & & & & & & & $\begin{array}{l}\text { gative } \\
\text { ank }\end{array}$ & & $\begin{array}{l}\text { sitive } \\
\text { lank }\end{array}$ & Ties & $\mathrm{Z}$ & $P$ \\
\hline $\begin{array}{l}\text { Measurement } \\
\text { Place }\end{array}$ & $\mathrm{n}$ & Mean & Median & Min. & Max. & SS & $\mathrm{N}$ & $\begin{array}{l}\text { Mean } \\
\text { Rank }\end{array}$ & $\mathrm{N}$ & $\begin{array}{l}\text { Mean } \\
\text { Rank }\end{array}$ & $\mathrm{n}$ & & \\
\hline Chest & 43 & $-0,016$ & 0,000 & $-0,500$ & 0,500 & 0,131 & \multirow{2}{*}{11} & \multirow{2}{*}{10,1} & \multirow{2}{*}{9} & \multirow{2}{*}{10,9} & \multirow{2}{*}{23} & \multirow{2}{*}{$-0,253$} & \multirow{2}{*}{0,800} \\
\hline Hem & 43 & $-0,019$ & 0,000 & $-0,500$ & 0,400 & 0,110 & & & & & & & \\
\hline
\end{tabular}

$\mathrm{p}>0,05$

There was no significant difference between chest width and hem width differences as $\mathrm{p}=0,800(\mathrm{p}>0.05)$. It was found that the measurements complied with each other.

At the end of the applications, right-left shoulder width, right-left arm length and right-left sleeve opening of the products were compared and it was also found that the measurements complied with each other $(\mathrm{p}>0.05)$.

In the light of the findings, it was accepted that the results of the measurement controls by the program are true. It was also found that the measurement results obtained with the program was at the same reliability as those obtained by the quality control operator. It was determined in the applications that the measurement control process applied by the control operator on the ready-made garment at the final control could be made through image analysis method. The data obtained showed that the deviations in the measurement control were within tolerable limits. It is a striking feature in terms of the efficacy of the program.

\section{ADVANTAGES, DISADVANTAGES AND DIFFERENCES}

In a day, both working speed and accuracy are depending on worker's performance. It was observed that the efficiency of workers have been decreased towards end of the day. There are many factors which trigger this situation; worker's mood, tiredness, health problems. This study mainly aimed that this problem and success is supported with results. Adding computer vision was a step in reducing dependence on the employee. Another step that increases speed and accuracy is the calculation by the computer. Thus, dependence on human variable efficiency has disappeared.

Because garment products are more complex due to many factors such as pattern and colour, the system may have difficulty. Basic models have been selected for this experiment since it is one of the first researches. The solution is to re-train the pre-trained model with these complex garments. The model learns with the data set it is trained in and does not make mistakes easily from data set it learns.

When other studies in this field are examined, it is seen that edge detection algorithms similar to this study are used. Unlike other algorithms, Faster RCNN is more current and more accepted algorithm. This allows the study to remain up-to-date and to build a faster architecture using today's technological facilities to the fullest. Besides these, Inception network allows deeper network which means algorithm which has used could work on more complex process and provides to choose filter size.

\section{CONCLUSIONS}

Ready-made clothing industry is a production field vulnerable to defect formation because of its variety of both raw material and supplementary materials and the stages of model and production and with its intensive labour structure. For that reason, it is necessary that quality control automation that would be established for the defect detection for the ready-made garments should offer effective solutions and that the sophisticated and effective defect detection algorithms of the programs to be prepared which require expertise should be created.

In the light of the studies that have been carried out up till now, the current study which was determined that it was the first study carried out to show that image analysis method could be used in the measurement control of the finished ready-made garments will take its place as a new quality control method in the literature and will be a sample for the similar studies in the sector. By benefiting from the image analysis methods in the measurement control, measurement mistakes likely to result from the operator during the measurement will be prevented and the results will be more reliable. The application and evaluation of the measurement process will be taken from the operator's initiative and systematic evaluation and reporting will be possible. For 
that reason, it is recommended to improve the study and carry out researches into software being able to a make concurrent warning and reporting. It is also recommended to carry out some studies and improvements into system by taking into consideration of putting such limitations as model, quality parameters, to use special technologies to be applied in interlude controls in different departments of the ready-made clothing businesses and also in the control of different ready-made garments.

\section{REFERENCES}

1. Vuruşkan A, Bulgun E. 2013. Kişiye özel giysiler için vücuda uygunluk analizi. Tekstil ve Mühendis 20 (90), 42-53.

2. Chen K. 2005. Image analysis technology in the automatic measurement of garment dimensions. Asian Journal of Information Technology 4(9), 832-834.

3. Roknabadi AD, Latifi M, Saharkhiz S, Aboltakhty H. 2012. Human body measurement system in clothing using image processing. World Applied Sciences Journal 19 (1), 112-119.

4. Cao L, Jiang Y, Jiang M. 2010. Automatic measurement of garment dimensions using machine vision. Proceedings of the International Conference on Computer Application and System Modeling (ICCASM 2010) (V9-30)-(V9-33). Taiyuan, China.

\section{ACKNOWLEDGEMENTS}

The doctorate thesis with the title of "Using Image Analysis Method in the Quality Control of the Readymade Products" upon which the current study depends was supported by Gazi University Scientific Research Projects with the project no of 08/2010-17. Because of his contributions, we would like to thank to Prof. Uğur Baysal, the academic member of Hacettepe University, Department of Electricity - Electronics Engineering.

5. Li C, Xu Y, Xiao Y, Liu H, Feng M, Zhang D. 2017, June. Automatic measurement of garment sizes using image recognition. Proceedings of the International Conference on Graphics and Signal Processing ICGSP'17 (30-34), Singapore.

6. Ural Ö. 2012. Hazır Giyim Ürünlerinin Kalite Kontrolünde Görüntü Analiz Yönteminin Kullanılması (Unpublished Doctorate Thesis) Gazi University, Institute of Educational Sciences, Department of Clothing Industry, Teaching of Clothing Arts, Ankara. 
